\title{
Marcos legais da Educação Ambiental em Petrópolis (RJ): conquistas e retrocessos ${ }^{1}$
}

\author{
Legal frameworks of Environmental Education
} in Petrópolis (RJ): achievements and setbacks

\author{
Victor Novicki ${ }^{2}$ \\ victor.novicki@ucp.br \\ Ramiro Farjalla ${ }^{3}$ \\ farjalla.ramiro@gmail.com
}

\section{Resumo}

Este artigo objetiva, inicialmente, analisar como a temática ambiental é tratada na Lei Orgânica Municipal (LOM) e no Plano Municipal de Educação (PME) de Petrópolis, município do estado do Rio de Janeiro (RJ), enfatizando as concepções de meio ambiente, de desenvolvimento sustentável e de Educação Ambiental (EA) e, num segundo momento, desenvolver uma análise comparativa entre as políticas nacional, fluminense e petropolitana de EA. Conclui-se que poucas conquistas da EA crítica foram incorporadas à LOM ou ao PME. Apesar da política municipal de EA incorporar abordagens críticas das outras políticas, cabe destacar algumas ausências: (a) não trata da formação inicial e continuada de professores; (b) não cria órgão específico para coordenar o programa municipal de EA, nem incorpora a participação social nesse processo; (c) não inclui especificidades da rede de ensino ou dos problemas socioambientais locais.

Palavras-chave: Educação Ambiental, Lei Orgânica Municipal, Plano Municipal de Educação, Política Pública, Sustentabilidade, Meio Ambiente, Legislação, Petrópolis (RJ)

\begin{abstract}
This article aims to analyze how the environmental thematic is treated in the Municipal Organic Law (MOL) and the Municipal Education Plan (MEP) of Petrópolis, a county of Rio de Janeiro state (RJ), emphasizing the concepts of environment, sustainable development and Environmental Education (EE), and, in a second moment, develop a comparative analysis among national, state and municipal policies of EE. We concluded that few conquests of critical EE were incorporated to the MOL or to the MEP. Despite the municipal political incorporate critical approaches from other policies, it is worth pointing out some absences: (a) it does not deal with the initial and continuing training of teachers; (b) it does not create specific organ to coordinate municipal EE program, nor incorporates the social participation in this process; (c) it does not include specificities of the school network or of the local socio-environmental problems.

Keywords Environmental Education, Municipal Organic Law, Municipal Education Plan, Public Policy, Sustainability, environment, Legislation, Petrópolis (RJ)

\footnotetext{
${ }^{1}$ Este artigo foi extraído de um conjunto maior de reflexões contido na Pesquisa "Políticas e Práticas de Educação Ambiental em Petrópolis (RJ)" (NOVICKI, 2010), que recebeu apoio (APQ1) da Fundação Carlos Chagas Filho de Amparo à Pesquisa do Estado do Rio de Janeiro (FAPERJ).

${ }^{2}$ Doutor em Ciências Sociais (UNICAMP). Professor Adjunto do Programa de Pós-Graduação em Educação da Universidade Católica de Petrópolis (UCP).

${ }^{3}$ Advogado (USU). Especialização em Direito Ambiental (UCM). Mestre em Educação (UCP).
}

Revista Educação Online, n. 15, jan./abr. 2014, p. 78-102 


\section{Introdução}

A região serrana do estado do Rio de Janeiro ${ }^{4}$, onde se situa o município de Petrópolis, segundo Oliveira (2010), possui duas unidades espaciais distintas, no que se refere ao dinamismo econômico:

A primeira caracteriza-se por apresentar grande dinamismo, devido às atividades industriais e turísticas, abrangendo os municípios de Nova Friburgo, Teresópolis e Petrópolis. A segunda unidade engloba o restante da região e é caracterizada por um fraco desempenho econômico, em decorrência da baixa produtividade da pecuária extensiva, o que tem contribuído para o aumento do êxodo rural. A pouca atividade industrial existente nessa unidade da região não possui o dinamismo suficiente para alterar este quadro. (p. 35)

Petrópolis e Nova Friburgo são os principais polos regionais, exercendo influência em todos os municípios da região. Petrópolis, além de possuir um rico patrimônio históricoambiental (turismo), distingue-se por suprir municípios próximos com o seu comércio e serviços, bem como pelo setor industrial: Garboni (fabricação de moldes de termoplásticos e, principalmente, tampas plásticas), Carbografite (fabricação e exportação de produtos e serviços nas áreas de solda, segurança industrial e ferramentas), GE Celma (fabricação de motores aeronáuticos para uso comercial e militar, produção de sistemas mecânicos e elétricos para aeronaves, prestação de serviços de manutenção para turbinas), Aalborg (caldeiras industriais) (NOVICKI, 2010).

Além dos problemas inerentes aos centros urbanos: infraestrutura, transporte urbano, coleta e destinação do lixo ${ }^{5}$, as principais atividades que interferem de forma direta e indireta na conservação dos recursos naturais da Área de Preservação Ambiental de Petrópolis e, consequentemente, do município de Petrópolis, são:

exploração de atividades agropecuárias extensivas, inclusive em margens de rios e encostas íngremes e topos de morros; utilização de práticas agrícolas prejudiciais à conservação do solo; expansão de áreas urbanas, condomínios e loteamentos rurais; queimadas; exploração de atividades mineradoras, extrativismo de recursos vegetais e animais; e existência de diversas atividades potencialmente poluidoras. (BRASIL.MMA.IBAMA, 2007, p. 3)

No enfrentamento da questão ambiental petropolitana, constatamos, a partir de levantamento realizado em 2011 e 2012, a existência de programas, projetos e atividades de Educação Ambiental (EA), desenvolvidos pela Companhia Municipal de Desenvolvimento de Petrópolis (COMDEP) - palestras em escolas sobre coleta seletiva - e pelas secretarias

\footnotetext{
${ }^{4}$ Essa região é composta por 14 municípios: Bom Jardim, Carmo, Cantagalo, Cordeiro, Duas Barras, Macuco, Nova Friburgo, Petrópolis, Santa Maria Madalena, São José do Vale do Rio Preto, São Sebastião do Alto, Sumidouro, Teresópolis, Trajano de Morais.

${ }^{5}$ Segundo a empresa Águas do Imperador, integrante do grupo Águas do Brasil, Petrópolis ocupa o segundo lugar no âmbito estadual e vigésimo sexto no nacional no tratamento de água e esgoto (FARJALLA, 2013).
}

Revista Educação Online, n. 15, jan./abr. 2014, p. 78-102 
municipais (a) de Educação (SEMED) - visitas de escolas às estações de tratamento de água e de esgoto, Programa Elos de Cidadania, em parceria com a Secretaria de Estado do Ambiente, visando à formação continuada de professores, Projeto Água, O Mundo Faz e Conta, Meu Querido Pau Brasil, Programa Nacional de Conservação de Energia Elétrica, Programa Nestlé Cuidar, Projeto Recicla Tecidos -, e (b) de Meio ambiente e Desenvolvimento Sustentável (SMADS) - palestras em escolas, Caravana Ecológica -, em sua maioria, implementados em parceira com a iniciativa privada.

Da mesma forma, verificamos que Petrópolis não possuía uma política de EA ou um órgão que coordenasse/articulasse as diferentes ações desenvolvidas pelas secretarias municipais (Programa Municipal de Educação Ambiental). Nesse sentido, a Câmara Técnica de Educação Ambiental do Conselho Municipal de Meio Ambiente de Petrópolis (COMDEMA), considerando sua atribuição de "propor leis, normas e padrões relativos à proteção, conservação e recuperação do Meio Ambiente, visando à manutenção da qualidade de vida da população de Petrópolis" (PETRÓPOLIS, 2006, p.1), realizou várias reuniões de trabalho, entre abril e outubro de 2011, na Secretaria Municipal de Meio Ambiente e Desenvolvimento Sustentável (SMADS), visando a construir uma proposta (minuta) de Política Municipal de Educação Ambiental de Petrópolis ${ }^{6}$.

Aquilo que, a rigor, deveria se constituir em um documento preliminar a ser discutido amplamente pela sociedade foi, por iniciativa do poder legislativo, alterado e transformado no Projeto de Lei oㅡ 0689/2012, em 3 de abril de 2012, posteriormente votado e aprovado, em dezembro do mesmo ano, na Câmara Municipal, como lei que "institui princípios e diretrizes para a Política Municipal de Educação Ambiental no Município de Petrópolis" (PETRÓPOLIS, 2012b, p.1)

Entretanto, diferente do que propunha o documento produzido pela Câmara Técnica de Educação Ambiental do COMDEMA, intitulado "Minuta da Lei de Política Municipal de Educação Ambiental de Petrópolis" (PETRÓPOLIS, 2011), constatamos ausências importantes na lei aprovada, que dificultarão sua implementação e, principalmente, a participação e o controle social, o que será aqui explorado.

Este artigo inicia com uma contextualização dos marcos legais da EA em relação às inovações legais, políticas e institucionais ocorridas no campo da EA, visando, em um segundo momento, a analisar como a temática ambiental é tratada na Lei Orgânica e no Plano Municipal de Educação de Petrópolis (RJ), enfatizando as concepções de meio ambiente, de

\footnotetext{
${ }^{6}$ Participaram dessas reuniões representantes das seguintes instituições: SMADS, COMDEMA, SEMED, Instituto Samambaia de Ciência Ambiental (ISCA), Ordem dos Advogados do Brasil, Câmara Municipal, Universidade Católica de Petrópolis (os autores deste artigo), dentre outras.
}

Revista Educação Online, n. 15, jan./abr. 2014, p. 78-102 
desenvolvimento sustentável e de Educação Ambiental (EA) e que, finalmente, desenvolve uma análise comparativa entre as políticas nacional, fluminense e petropolitana de EA.

\section{EA: conferências internacionais, legislação e política educacional brasileira}

Visando a contextualizar estes documentos: Lei Orgânica, Plano Municipal de Educação e Política Municipal de EA de Petrópolis, na trajetória recente das inovações legais, políticas e institucionais no campo da educação ambiental nacional e fluminense, elencamos abaixo importantes eventos internacionais sobre a questão ambiental, bem como a legislação e as políticas brasileiras sobre essa temática, de modo a poder analisar esses marcos legais em suas respectivas conjunturas, tendo como referência cinco momentos: $1^{\circ}$ ) Lei Orgânica (LOM) em abril de 1990 (PETRÓPOLIS, 1990); 2º) Terceira Edição Anotada da LOM, em dezembro de 2000 (PETRÓPOLIS, 2000); 3ํ) revisão da LOM, através da Emenda oㅡ 25, de 10 de outubro de 2012 (PETRÓPOLIS, 2012a); 4) Plano Municipal de Educação, em dezembro de 2009 (PETRÓPOLIS, 2009b; PETRÓPOLIS, 2009); e 5º) Política Municipal de EA (PETRÓPOLIS, 2012b):

a) quatro conferências internacionais que discutiram a relação entre desenvolvimento econômico e conservação ambiental (desenvolvimento sustentável): a Conferência de Estocolmo, ocorrida em 1972, a Eco-92, a Cúpula Mundial sobre Desenvolvimento Sustentável (CMDS), realizada em Johanesburgo (África do Sul) em 2002, a Conferência das Nações Unidas sobre Desenvolvimento Sustentável (Rio + 20), realizada na cidade do Rio de Janeiro, em junho de 2012, produzindo o documento final intitulado $O$ futuro que queremos, que define o desenvolvimento sustentável como meta e a Gestão Ambiental e a Educação Ambiental como importantes instrumentos nesse processo;

b) sete eventos internacionais que trataram exclusivamente da educação ambiental: a Conferência de Tbilisi, ocorrida em 1977, a Conferência de Moscou (1987), o Fórum das Organizações Não-Governamentais e Movimentos Sociais, evento paralelo à Eco-92, que produziu o Tratado de Educação Ambiental para Sociedades Sustentáveis e Responsabilidade Global, a III Conferência Internacional sobre Meio Ambiente e Sociedade: Educação e Consciência Pública para a Sustentabilidade (Thessaloniki, em 1997), a IV Conferência Internacional de Educação Ambiental (Ahmedabad, em 2007), evento paralelo à Rio+20, Cúpula dos Povos, que produziu o documento Em defesa dos bens comuns, contra a mercantilização da vida, em junho de 2012, e, por fim, a Conferência Intergovernamental sobre Educação Ambiental para o Desenvolvimento Sustentável (Tbilisi+35), que gerou o documento 
Comunicado de Tbilisi - Educar hoje para um futuro sustentável, que definem princípios, diretrizes e objetivos da Educação Ambiental;

c) em nível nacional, a Política Nacional do Meio Ambiente (BRASIL, 1981), a Constituição Federal (BRASIL, 1988), a Política Nacional de Educação Ambiental (BRASIL, 1999) e a Política Estadual de Educação Ambiental do Rio de Janeiro (RIO DE JANEIRO, 1999), que determinam a inserção da educação ambiental, de modo interdisciplinar e transversal, nos diferentes níveis e modalidades de ensino;

d) no âmbito da política educacional, ocorreu a edição, para o ensino fundamental, dos Parâmetros Curriculares Nacionais (PCN)/Tema Transversal: Meio Ambiente (BRASIL, 1997a, 1997b, 1998a, 1998b), do Referencial Curricular Nacional da Educação Infantil (BRASIL, 1998c), do Programa Parâmetros em Ação (BRASIL, 2001), visando à formação continuada de professores do ensino fundamental, a regulamentação da Política Nacional de Educação Ambiental - PNEA (BRASIL, 1999), pelo Decreto no 4.281, de 25 de junho de 2002 (BRASIL, 2002), que também criou o Órgão Gestor da Política Nacional de Educação Ambiental (OGPNEA), articulando os ministérios do Meio Ambiente e da Educação ${ }^{7}$, que, por sua vez, elaborou o Programa Nacional de Educação Ambiental (ProNEA) (BRASIL, 2005), o Programa Nacional de Formação de Educadoras(es) Ambientais - ProFEA (BRASIL, 2006) e as Diretrizes Curriculares Nacionais para a Educação Ambiental (BRASIL, 2012), em setembro de 2012.

Isso significa que, em princípio, os legisladores petropolitanos - com apoio das secretarias municipais de Educação (SEMED) e de Meio Ambiente e Desenvolvimento Sustentável (SMADS), da Companhia Municipal de Desenvolvimento de Petrópolis (COMDEP), dos conselhos municipais de Meio Ambiente (COMDEMA) e de Educação (COMED), de organizações não governamentais, dos governos estadual ${ }^{8}$ e federal, das universidades, dentre outros atores sociais - poderiam, nos cinco momentos anteriormente destacados, inserir essas inovações legais, políticas e institucionais, a rigor, conquistas dos movimentos ambientalistas, na Lei Orgânica (PETRÓPOLIS, 1990, 2000, 2012a), no Plano Municipal de Educação (PETRÓPOLIS, 2009) e, posteriormente, na Política de Educação Ambiental (PETRÓPOLIS, 2012b) do município de Petrópolis, o que será discutido a seguir.

\section{Lei Orgânica e Plano Municipal de Educação de Petrópolis}

\footnotetext{
${ }^{7}$ No estado do Rio de Janeiro, através do Decreto $n^{\circ} 27.559$, de 18/12/2000, foi criado o Grupo Interdisciplinar de Educação Ambiental do Estado do Rio de Janeiro (GIEA), formado por representantes dos órgãos de Meio Ambiente, Educação, Cultura, Ciência e Tecnologia, universidades, organizações não governamentais, dentre outros, que têm a responsabilidade do acompanhar da Política Estadual de Educação Ambiental.

${ }^{8} \mathrm{O}$ governo fluminense possui nas secretarias de Educação e do Ambiente, respectivamente, a Coordenação Estadual de Educação Ambiental (CEEA/SEEDUC) e a Superintendência de Educação Ambiental (SEAM/SEA).
}

Revista Educação Online, n. 15, jan./abr. 2014, p. 78-102 
A Lei Orgânica do Município de Petrópolis, promulgada em 05 de abril de 1990 (PETRÓPOLIS, 1990), foi, segundo Petrópolis (2000), "enriquecida com mais de cento e oitenta NOTAS, preparadas pela Equipe [do] Departamento Jurídico" (p.2), gerando uma Terceira Edição Anotada, em 15 de dezembro de 2000, que, em outubro de 2012, passou por um processo de revisão, através da Emenda no 25, de 10 de outubro de 2012, que será objeto da presente análise (PETRÓPOLIS, 2012a) . $^{9}$

Outro marco legal que trata da educação ambiental em Petrópolis consiste no Plano Municipal de Educação (PETRÓPOLIS, 2009b; PETRÓPOLIS, 2009), elaborado entre 2006 e 2008, estruturado em 'diagnóstico', 'diretrizes', 'objetivos' e 'metas', relativos aos diferentes níveis e modalidades de ensino.

Inicialmente, nosso objetivo é analisar como a temática ambiental é tratada nesses documentos, através, principalmente, das seguintes categorias: desenvolvimento sustentável, meio ambiente e educação ambiental, cujas diferentes concepções serão discutidas simultaneamente à apresentação dessas leis.

Na Lei Orgânica do Município de Petrópolis (PETRÓPOLIS, 2012a), a preocupação com a questão ambiental está presente em diferentes políticas setoriais: saúde ("Art. 134, II respeito ao meio ambiente e controle da poluição ambiental"); educação ("Art. 143, § 50 - os Currículos escolares serão adequados às peculiaridades do município e à valorização de sua cultura [e d]o seu patrimônio histórico, artístico, cultural e ambiental"), política urbana ("Art. 169, V - criação de áreas de especial interesse urbanístico, ambiental, de lazer, turístico e de utilização pública"); política econômica (“Art. 155 - Na promoção do desenvolvimento econômico, o município agirá, sem prejuízo de outras iniciativas, no sentido de: $\mathrm{V}$ - proteger o meio ambiente"); política agrária ("Art. 176, IV - planejar e implementar a política de desenvolvimento agrícola compatível com a política agrária e com a preservação do meio ambiente e conservação do solo, estimulando os sistemas de produção integrados, a policultura orgânica e a integração entre agricultura, pecuária, apicultura e aquicultura"); saneamento ("Art. 184 - O abastecimento de água, a coleta e a disposição adequada de esgotos, o tratamento e a destinação dos resíduos sólidos e a drenagem das águas pluviais deverão ser executados, observando-se, entre outros, os seguintes preceitos: III - a preservação do equilíbrio ecológico") e, em um capítulo específico, a política ambiental ("Da Política do Meio Ambiente e dos Produtos Tóxicos"). Isso poderia indicar que, além de alocar a temática do meio ambiente em órgãos voltados para a solução técnica da questão ambiental, entende-se a educação como um importante instrumento da gestão ambiental pública e

\footnotetext{
${ }^{9}$ Cabe destacar que, a partir dessa versão da LOM (Art. 191, parágrafo $2^{\circ}$ ), o COMDEMA passa a participar na gestão do Fundo Municipal de Conservação Ambiental (PETRÓPOLIS, 2012a).

Revista Educação Online, n. 15, jan./abr. 2014, p. 78-102
} 
privada, conforme preconiza a política educacional brasileira. Entretanto, como constataremos, essa expectativa será frustrada...

Organizamos esta parte do texto em torno das nossas categorias centrais de análise, ou seja, desenvolvimento sustentável, meio ambiente e educação ambiental.

\section{Desenvolvimento Sustentável}

Em 1973, no ano seguinte à realização da Conferência de Estocolmo, Maurice Strong cunhou o conceito de ecodesenvolvimento, que consistiu

na definição de um estilo de desenvolvimento adaptado às áreas rurais do Terceiro Mundo, baseado na utilização criteriosa dos recursos locais, sem comprometer o esgotamento da natureza, pois nesses locais ainda havia a possibilidade de tais sociedades não se engajarem na ilusão do crescimento mimético. Com a Declaração de Cocoyoc no México em 1974, também as cidades do Terceiro Mundo passam a ser consideradas no ecodesenvolvimento. Finalmente, na década de 80, o economista Ignacy Sachs se apropria do termo e o desenvolve conceitualmente, criando um quadro de estratégias ao ecodesenvolvimento. Parte da premissa desse modelo se baseia em três pilares: eficiência econômica, justiça social e prudência ecológica. (LAYRARGUES, 1997, p. 3)

Posteriormente, uma primeira concepção de desenvolvimento sustentável origina-se no interior do discurso desenvolvimentista e é defendida pelo Estado e empresariado (DELUIZ; NOVICKI, 2004). Foi proclamada pelo Relatório Brundtland (1987), produzido pela Comissão Mundial sobre Meio Ambiente e Desenvolvimento da ONU: desenvolvimento sustentável é aquele que "atende às necessidades do presente sem comprometer a possibilidade de as gerações futuras atenderem às suas próprias necessidades" (ACSELRAD; LEROY, 1999, p. 17), isto é, aquele que garante um crescimento econômico vigoroso e, ao mesmo tempo, social e ambientalmente sustentável. O diagnóstico e as propostas para a superação da crise ambiental devem ser pautadas no mercado, pela via da aceleração do desenvolvimento econômico, acompanhado da maciça transferência de recursos dos países centrais para os países subdesenvolvidos, na forma de assistência financeira e tecnológica (LAYRARGUES, 1997; ACSELRAD; LEROY, 1999; DELUIZ; NOVICKI, 2004).

No ano seguinte, a Constituição Federal (BRASIL, 1988), de maneira não explícita, contemplava preocupação em torno de uma solidariedade intergeracional, visando a garantir o direito de todos "ao meio ambiente ecologicamente equilibrado", aproximando-se da definição de desenvolvimento sustentável proposta pelo Relatório Brundtland:

\section{CAPÍTULO VI - DO MEIO AMBIENTE}

Art. 225. Todos têm direito ao meio ambiente ecologicamente equilibrado, bem de uso comum do povo e essencial à sadia qualidade de vida, impondo-se ao Poder Público e à coletividade o 
dever de defendê-lo e preservá-lo para as presentes e futuras gerações. (BRASIL, 1988, grifos nossos) $)^{10}$

Entretanto, somente com a realização da Conferência das Nações Unidas para o Meio Ambiente e Desenvolvimento, no Rio de Janeiro, em 1992 (também conhecida por Rio-92) (CNUMAD, 1992), o termo desenvolvimento sustentável viria a se popularizar.

Em evento paralelo à Rio-92, no Aterro do Flamengo, ocorreu o Fórum das Organizações Não Governamentais e Movimentos Sociais, que produziu o Tratado de Educação Ambiental para Sociedades Sustentáveis e Responsabilidade Global (TEASS) que, diferente da lógica do mercado defendida pelo enfoque do desenvolvimento sustentável, tem como objetivo a construção de sociedades sustentáveis. Sob uma perspectiva crítica, sem desconsiderar os avanços tecnológicos - que não são colocados a serviço de todos os seres humanos -, a sustentabilidade é entendida como o "processo pelo qual as sociedades administram as condições materiais de sua reprodução, redefinindo os princípios éticos e sociopolíticos que orientam a distribuição de seus recursos ambientais" (ACSELRAD; LEROY, 1999, p. 28). Tal concepção, fundada na equidade enquanto princípio das sociedades sustentáveis, possui pressupostos que se ancoram na tradição marxista da crítica à economia política, ou seja, voltam-se para o exame crítico das sociedades que se organizam em torno da propriedade privada dos meios de produção, da subsunção do trabalho ao capital e da lógica do processo de acumulação capitalista (MARX, 1988). Trata-se de um tipo de análise, portanto, que se pauta na crítica ao modelo de desenvolvimento capitalista e, consequentemente, nos pressupostos que norteiam a noção de sociedade sustentável, revelando-nos a necessidade de construção

de alternativas societárias democráticas que superem a desigualdade social e a degradação das próprias bases materiais do modo de produção. Permite-nos compreender [...] que na concepção da sustentabilidade na lógica democrática, a relação trabalho e meio ambiente não está subsumida à hegemonia do capital, [...mas à] perspectiva de ampliação da qualidade de vida das populações e de superação da desigualdade/exclusão social e da desigualdade socioambiental. (DELUIZ; NOVICKI, 2004, p. 24)

Assim, em princípio, a Lei Orgânica do Município de Petrópolis poderia fazer menção ao ecodesenvolvimento (expressão cunhada em 1973), ao desenvolvimento sustentável (proposta criada em 1987, popularizada em 1992) e/ou às sociedades sustentáveis, apesar de suas diferentes perspectivas societárias. Todavia, não encontramos referências, ao buscarmos as palavras-chave "desenvolvimento sustentável", "sustentabilidade" ou "sociedades sustentáveis" nesta Lei Orgânica Municipal (PETRÓPOLIS, 2012a).

\footnotetext{
${ }^{10}$ Disponível em <http://www.planalto.gov.br/ccivil_03/constituicao/constituicaocompilado.htm>. Acesso em: 17 mar. 2014.
}

Revista Educação Online, n. 15, jan./abr. 2014, p. 78-102 
Nesse documento, a ideia de desenvolvimento sustentável está, por um lado, restrita à noção de autossustentabilidade local (aproveitamento dos recursos naturais locais), nas seções que tratam "Da Política Agrícola e Fundiária” ("Art. 176, III - incentivar, através de programas previamente discutidos com a comunidade, a utilização de recursos energéticos locais, como forma de aproveitamento autossustentado do ecossistema", "Art. 180 - Compete ao município planejar o desenvolvimento rural em seu território, observado o disposto na Constituição Federal e Estadual, de forma a garantir o uso rentável e autossustentável dos recursos disponíveis") e, por outro, de modo mais explícito nas seções (a) "Da Política do Meio Ambiente e dos Produtos Tóxicos" (“Art. 190, § 1ํ, XI - instituir o planejamento ambiental dos recursos naturais renováveis gerenciando e fiscalizando a sua utilização racional e sustentada manejando-a corretamente") e (b) "Da Política Econômica” (“Art. 155 - Na promoção do desenvolvimento econômico, o município agirá, sem prejuízo de outras iniciativas, no sentido de: V - proteger o meio ambiente"). Cabe destacar a tensão presente, nessas duas últimas seções, entre a racionalidade/rentabilidade das atividades econômicas e a sustentabilidade ambiental, própria das discussões relativas ao desenvolvimento sustentável, à sustentabilidade.

Por seu turno, no Plano Municipal de Educação (PETRÓPOLIS, 2009b; PETRÓPOLIS, 2009), a questão da sustentabilidade é abordada no capítulo referente à Educação de Jovens e Adultos, sem, entretanto, explicitar o entendimento sobre como concebe desenvolvimento sustentável:

\section{EDUCAÇÃO DE JOVENS E ADULTOS}

1. Diagnóstico (...)

1.2. Políticas Públicas

Tais projetos se propõem a estabelecer uma proposta de EJA a partir da realidade específica da população petropolitana e voltada para essa. Objetiva enfrentar o analfabetismo no município, partindo-se da compreensão de que é possível, no processo em que o alfabetizando adquire as habilidades que Ihe possibilitarão ler e escrever, criar consciência cidadã de forma científica, ter noções que já fazem parte de seu trabalho e de sua vida: conhecimentos nas áreas da saúde, saneamento e habitabilidade, desenvolvimento sustentável, cooperativismo e associativismo, convivência em comunidade, sociedade em que vive e produz (PETRÓPOLIS, 2009, p. 54, grifos nossos).

\section{Meio Ambiente}

Nos âmbitos da Política Nacional do Meio Ambiente (PNMA), em seu Artigo 2º, da Constituição Federal de 1988, Artigo 225ํㅡㄹ e da Política Nacional de Educação Ambiental, Artigo $1^{\circ}$, o meio ambiente é entendido como "patrimônio público" (BRASIL, 1981) e "bem de uso comum do povo" (BRASIL, 1988, 1999; RIO DE JANEIRO, 1999), cabendo "ao poder público" (BRASIL, 1981), "ao poder público e à coletividade" (BRASIL, 1988) e "ao indivíduo e à 
coletividade" (BRASIL, 1999; RIO DE JANEIRO, 1999) a responsabilidade pela preservação/conservação ambiental.

Na Lei Orgânica do Município de Petrópolis (PETRÓPOLIS, 2012a), esse aspecto é tratado na seção que aborda a política urbana: nela, o meio ambiente segue a Constituição Federal de 1988, quando afirma que se trata de um "bem de uso comum do povo" (BRASIL, 1988).

Outro aspecto de interesse para este estudo diz respeito à concepção de meio ambiente constante na Lei Orgânica do Município de Petrópolis. Apresentamos, preliminarmente, as distintas concepções de meio ambiente, presentes na Política Nacional do Meio Ambiente (BRASIL, 1981) e nas políticas nacional e fluminense de Educação Ambiental (BRASIL, 1999; RIO DE JANEIRO, 1999):

Art $3^{\circ}$ - Para os fins previstos nesta Lei, entende-se por:

I - meio ambiente, o conjunto de condições, leis, influências e interações de ordem física, química e biológica, que permite, abriga e rege a vida em todas as suas formas (BRASIL, 1981)

Art. $4^{\circ}$ - São princípios básicos da educação ambiental:

II - a concepção do meio ambiente em sua totalidade, considerando a interdependência entre o meio natural, o socioeconômico e o cultural, sob o enfoque da sustentabilidade (BRASIL, 1999)

Art. 4ํ - São objetivos fundamentais da educação ambiental:

I - O desenvolvimento de uma compreensão integrada do meio ambiente e suas múltiplas e complexas relações, envolvendo aspectos ecológicos, psicológicos, legais, políticos, sociais, econômicos, científicos, culturais e éticos; (RIO DE JANEIRO, 1999)

Enquanto as Políticas Nacional e Fluminense de Educação Ambiental (BRASIL, 1999; RIO DE JANEIRO, 1999) destacam como um princípio básico o entendimento que considera as dimensões social, política, cultural e econômica do meio ambiente, a Política Nacional do Meio Ambiente (BRASIL, 1981) não ultrapassa seus aspectos biológicos ("interações de ordem física, química e biológica"). Essa conquista dos movimentos ambientalistas não foi incorporada à Lei Orgânica de Petrópolis (PETRÓPOLIS, 2012a), pois apresenta uma concepção reducionista de meio ambiente (GUIMARÃES, 2004), ou seja, restrita aos aspectos naturais do meio ambiente, consistindo num dualismo Homem-natureza que impossibilita o desenvolvimento de uma Educação Ambiental crítica (GRÜN, 1996): "Seção V - Da Política Urbana, Art. 161, VI) meio ambiente ecologicamente equilibrado, bem de uso comum do Povo e essencial à sadia qualidade de vida conservando, preservando e restaurando os processos naturais" (PETRÓPOLIS, 2012), semelhante à Política Nacional do Meio Ambiente (BRASIL, 1981).

Entretanto, de maneira distinta, na seção específica para a temática ambiental ("Da Política do Meio Ambiente e dos Produtos Tóxicos"), a Lei Orgânica de Petrópolis 
(PETRÓPOLIS, 2012a) apresenta, além de uma coparticipação da comunidade, uma concepção socioambiental de meio ambiente (GUIMARÃES, 2004), que incorpora o ser humano, seus valores e interesses, semelhante às Políticas Nacional e Fluminense de Educação Ambiental (BRASIL, 1999; RIO DE JANEIRO, 1999):

Seção VIII - Da Política do Meio Ambiente e dos Produtos Tóxicos

Art. 190 - O município providenciará, com a participação da comunidade, em articulação com o Estado e a União Federal, a preservação, conservação, defesa, recuperação e melhoria do meio ambiente natural, artificial e do trabalho, atendidas as peculiaridades regionais e locais e em harmonia com o desenvolvimento social e econômico. (PETRÓPOLIS, 2012a, grifos nossos)

Enquanto a Lei Orgânica do Município apresenta concepções contraditórias de meio ambiente - reducionista e socioambiental -, em diferentes momentos do documento, constatamos que o Plano Municipal de Educação sequer menciona "meio ambiente".

\section{Educação Ambiental}

Há mais de três décadas, existe a determinação legal de que a educação ambiental deve estar presente em todos os níveis e modalidades de ensino, conforme preconizaram a Política Nacional do Meio Ambiente (BRASIL, 1981) e a Constituição Federal (BRASIL, 1988), o que viria a ser ratificado pelas políticas nacional e fluminense de Educação Ambiental (BRASIL, 1999; RIO DE JANEIRO, 1999), que a definem em uma perspectiva crítica (LAYRARGUES; LIMA, 2011), como uma tematização de valores:

Capítulo I - Da Educação Ambiental

Art. 1ํ. Entende-se por educação ambiental os processos por meio dos quais o indivíduo e a coletividade constroem valores sociais, conhecimentos, habilidades, atitudes e competências voltadas para a conservação do meio ambiente, bem de uso comum do povo, essencial à sadia qualidade de vida e sua sustentabilidade. (BRASIL, 1999)

Art. $1^{\circ}$ - Entende-se por educação ambiental os processos através dos quais o indivíduo e a coletividade constroem valores sociais, conhecimentos, atitudes, habilidades, interesse ativo e competência voltados para a conservação do meio ambiente, bem de uso comum do povo, essencial à sadia qualidade de vida e sua sustentabilidade. (RIO DE JANEIRO, 1999)

Existe apenas uma menção à "educação ambiental" na Lei Orgânica do Município de Petrópolis (PETRÓPOLIS, 2012a) que, além de não defini-la, chama a atenção o fato de a Educação Ambiental não ser também uma atividade do poder público, a quem competiria apenas estimular e apoiar a sociedade civil organizada, caracterizando uma "educação conservacionista", ou seja, voltada exclusivamente para a conservação da natureza, sem menção à sociedade que degrada o meio ambiente (LAYRARGUES; LIMA, 2011):

Seção VIII - Da Política do Meio ambiente e dos Produtos Tóxicos

Art. 190, $\S 1^{\circ}$ - Além do previsto nas Constituições Federal e Estadual, para assegurar a efetividade dessas medidas, incumbe ao Poder Público Municipal: 
VII - incentivar as entidades associativas e as diversas formas organizadas da população à Participação no processo de Educação Ambiental e da conservação da natureza com estímulos e apoio do município. (PETRỎPOLIS, 2012a, grifos nossos)

Encontramos ainda outras menções à articulação entre educação e meio ambiente, como nas seções "Política Educacional, Cultural e Desportiva" ("Art. 143, V, § 5ㅇ - Os Currículos escolares serão adequados às peculiaridades do Município e à valorização de sua cultura [e d]o seu patrimônio histórico, artístico, cultural e Ambiental"), na "Política Agrícola e Fundiária” (“Art. 176, VII - instituir programas de ensino agrícola associado ao ensino não formal e à Educação para preservação do meio ambiente"), e na "Política do Meio ambiente e dos Produtos Tóxicos":

Art. 196. A Comissão Municipal de Controle de Agrotóxicos e outros Biocidas - COMCAB, criada por lei, responsável pela implantação de um programa multidisciplinar nas áreas de saúde, educação, vigilância sanitária, extensão rural e mobilização comunitária, visando à preservação da saúde humana e ambiental quanto ao uso dos produtos agrotóxicos.

$\S 1^{\circ}$ A COMCAB tem finalidade eminentemente educacional e preventiva. (PETRÓPOLIS, 2012a)

O Plano Municipal de Educação de Petrópolis determina que a Educação Ambiental seja abordada de modo transversal às disciplinas do ensino fundamental, conforme preconizado pela política educacional (BRASIL, 1997b, 1998b), bem como pelos princípios propostos pela Política Nacional (BRASIL, 1999) e Fluminense (RIO DE JANEIRO, 1999) de Educação Ambiental:

\section{ENSINO FUNDAMENTAL}

3. Objetivos e Metas

3.1 Objetivos

9. Assegurar que a Educação Ambiental seja tratada como tema transversal e desenvolvida como uma prática educativa integrada, contínua e permanente em conformidade com a lei no 9795/99, nas escolas da rede municipal de ensino. (PETRÓPOLIS, 2009, p. 30)

Outra lei, que detectamos em nossa pesquisa (PETRÓPOLIS, 2009a), se propõe a incluir entre os temas transversais propostos pelo $\mathrm{MEC}^{11}$, noções gerais de defesa civil e percepção de riscos:

Art. 1ํ Ficam incluídos entre os temas transversais a serem trabalhados por todos os professores do ensino fundamental e do ensino médio da rede pública municipal os temas Noções Gerais de Defesa Civil e Percepção de Riscos.

Art. $2^{\circ}$ Os professores da rede pública de ensino municipal serão capacitados para atender os fins previstos nesta Lei.

Parágrafo único. O Poder Executivo através de regulamentação designará órgão da administração responsável pela referida capacitação.

\section{Políticas nacional, fluminense e petropolitana de Educação Ambiental}

\footnotetext{
${ }^{11}$ Os Parâmetros Curriculares Nacionais criaram seis temas transversais para o ensino fundamental: ética, saúde, orientação sexual, pluralidade cultural, meio ambiente, trabalho e consumo (BRASIL.MEC.SEF, 1997a, 1998a).
}

Revista Educação Online, n. 15, jan./abr. 2014, p. 78-102 
Neste tópico, desenvolveremos uma análise comparativa entre as políticas nacional (BRASIL, 1999), fluminense (RIO DE JANEIRO, 1999) e petropolitana (PETRÓPOLIS, 2012b) de educação ambiental, visando a identificar em que medida uma perspectiva crítica ao nosso modo de produção e consumo, presente na legislação nacional e estadual, foi incorporada pela política petropolitana.

Cabe destacar, de imediato, dois aspectos: $1^{\circ}$ ) desde 1999, com a publicação da Política Estadual de Educação Ambiental (RIO DE JANEIRO, 1999), poderia ter sido criada a Política Municipal de Educação Ambiental de Petrópolis, o que só veio a ocorrer treze anos depois; 2º) a rigor, diferente das leis que instituem as políticas nacional e fluminense, a legislação petropolitana se restringe a instituir "princípios e diretrizes para a Política Municipal de Educação Ambiental" (PETRÓPOLIS, 2012b) ${ }^{12}$.

Para realização desta análise comparativa, montamos um quadro que decompõe as políticas nacional, fluminense e petropolitana em tópicos/assuntos, o que facilitou a identificação de semelhanças e diferenças, conforme apresentamos a seguir ${ }^{13}$ :

a) definição de Educação Ambiental (EA), de seus objetivos/finalidades (Art. 1), bem como os níveis e modalidades de ensino a serem atendidos (Art. 2): trata-se de cópia das políticas nacional (BRASIL, 1999) e fluminense (RIO DE JANEIRO, 1999), que incorpora, por um lado, o objetivo de construir o "interesse ativo", conforme a política fluminense e, por outro, a finalidade de "participação ativa", originalmente proposta na Política Nacional do Meio Ambiente (BRASIL, 1981), caracterizando-se como uma concepção crítica de Educação Ambiental (LAYRARGUES; LIMA, 2011):

Art. $1^{\circ}$ - Esta Lei estabelece princípios e diretrizes para a Política de Educação Ambiental no município de Petrópolis.

Parágrafo único - Entende-se por educação ambiental os processos por meio dos quais o indivíduo e a coletividade constroem valores sociais, conhecimentos, habilidades, atitudes, interesse ativo e competências voltadas para a participação ativa na preservação do meio ambiente, bem de uso comum do povo, essencial à sadia qualidade de vida e sua sustentabilidade.

Art. $2^{ }$- A educação ambiental é um componente essencial e permanente da educação municipal, devendo estar presente, de forma articulada, em todos os níveis e modalidades do processo educativo, em caráter formal e não formal. (PETRÓPOLIS, 2012b)

b) considerando que todos têm direito à $E A$, a legislação analisada delega a diferentes atores sociais o desenvolvimento da EA (Art. $3^{\circ}$ ), conforme os elencados na política nacional (poder público, instituições educativas, meios de comunicação de massa, empresas, entidades

\footnotetext{
${ }^{12}$ A Minuta de Projeto de Lei possuía uma outra redação: "Art. 6º Fica instituída a Política Municipal de Educação Ambiental e o Sistema Municipal de Educação Ambiental" (PETRÓPOLIS, 2011).

${ }^{13}$ Considerando o limite de páginas deste artigo, optamos por destacar as semelhanças e diferenças existentes entre as leis analisadas e, para um melhor entendimento dos comentários aqui desenvolvidos, disponibilizamos links para as políticas nacional, fluminense e petropolitana, bem como para outras referências no item Referências bibliográficas.
}

Revista Educação Online, n. 15, jan./abr. 2014, p. 78-102 
de classe, instituições públicas e privadas, "sociedade como um todo"). Cabe destacar que, na política estadual e na petropolitana, estão incluídos "as organizações não governamentais e movimentos sociais". Entretanto, a legislação petropolitana, diferente da federal (Sistema Nacional de Meio Ambiente) ${ }^{14}$ e da estadual (Sistema Estadual de Meio Ambiente), não faz menção à existência ou à criação de um Sistema Municipal de Meio Ambiente de Petrópolis, fundamental para a implementação da política municipal de Educação Ambiental;

c) dentre os princípios básicos da educação ambiental, quase idênticos nas três leis, destacamos o inciso II, que apresenta uma concepção socioambiental de meio ambiente, ou seja, aquela que abrange a natureza, o ser humano e a "tensão" existente entre eles (esgotamento e poluição do meio ambiente), explicitando a existência de uma relação de interdependência (dialética) entre Homem e natureza/meio ambiente (GRÜN, 1996):

Art. 4ํ- São princípios básicos da educação ambiental:

II - a concepção do meio ambiente em sua totalidade, considerando a interdependência entre o meio natural, o socioeconômico e o cultural, sob o enfoque da sustentabilidade. (PETRÓPOLIS, 2012b) ${ }^{15}$;

d) além dos objetivos fundamentais da educação ambiental, constantes na política federal (compreensão integrada do meio ambiente, democratização das informações ambientais, participação individual e coletiva, dentre outros), a política estadual e petropolitana, com redações diferentes, incluem uma especificidade fluminense: "V - O fortalecimento dos princípios de respeito aos povos tradicionais e comunidades locais e de solidariedade internacional como fundamentos para o futuro da humanidade" (RIO DE JANEIRO, 1999). Em relação à política federal, a lei petropolitana altera a redação de um inciso: "III - o estímulo e o fortalecimento de uma consciência crítica sobre a problemática ambiental e social" (BRASIL, 1999), acrescentando, ao final desse objetivo, "inclusive quanto à responsabilidade do homem" (PETRÓPOLIS, 2012b), o que nos parece desnecessário, pois a consciência crítica não diz respeito à fauna ou à flora... A lei petropolitana também inclui como objetivo fundamental "VIII O desenvolvimento de uma conscientização voltada para as práticas de consumo consciente";

e) as leis definem de modo idêntico os atores envolvidos na implementação dessas políticas: órgãos do sistema nacional/estadual/municipal do meio ambiente, instituições

\footnotetext{
${ }^{14}$ A estruturação do Sisnama seria similar a uma rede de organizações, cabendo a ele a formulação de políticas públicas de meio ambiente, a articulação entre as instituições componentes do sistema em âmbitos federal, estadual e municipal e a execução dessas políticas por meio dos órgãos competentes. Nessas três esferas federadas (União, estados e municípios), os órgãos ambientais passam a ter, portanto, a responsabilidade de promover a troca de informações, a formação da consciência ambiental, a fiscalização e o licenciamento ambiental, além da criação de Comissões Tripartites, conselhos, órgãos e fundos de meio ambiente, buscando, ainda, estabelecer uma política ambiental integrada, no sentido de incluir essa questão nas demais políticas de governo (BRASIL, 2006).

${ }^{15}$ Cabe destacar que a política estadual inclui como princípio básico "VI - a participação da comunidade".
}

Revista Educação Online, n. 15, jan./abr. 2014, p. 78-102 
educacionais públicas e privadas, órgãos públicos e organizações não governamentais com atuação em educação ambiental

Art. 7ํ- A Política Estadual de Educação Ambiental engloba o conjunto de iniciativas voltadas para a formação de cidadãos e comunidades capazes de tornar compreensíveis a problemática ambiental e de promover uma atuação responsável para a solução dos problemas ambientais.

Art. 8o, Parágrafo único - As instituições de ensino básico, públicas e privadas, incluirão em seus projetos pedagógicos a dimensão ambiental, de acordo com os princípios e objetivos desta lei. (RIO DE JANEIRO, 1999).

Apesar de a lei municipal não ter atribuído incumbências aos órgãos integrantes do Sistema Municipal de Educação Ambiental, anteriormente no artigo $3^{\circ}$, como o fizeram as legislações nacional e estadual, agora, no artigo sexto, esse sistema é incorporado como um dos atores na implementação dessa política. A política estadual inova em relação à federal, pois a direciona para a compreensão e solução dos problemas ambientais, conforme recomendação da Conferência de Tbilisi, bem como quando determina a inclusão da dimensão ambiental nos projetos pedagógicos das instituições de ensino básico, sejam elas públicas ou privadas;

f) as linhas de atuação propostas pela política municipal são uma cópia da política estadual e nacional, sendo que essa última acrescenta: " $§ 1^{\circ}$ Nas atividades vinculadas à Política Nacional de Educação Ambiental serão respeitados os princípios e objetivos fixados por esta Lei":

Art. $7^{\circ}-$ As atividades vinculadas à Política de Educação Ambiental devem focar nas seguintes linhas de atuação, necessariamente inter-relacionadas:

I - Educação ambiental no ensino formal;

II - Educação ambiental não formal;

III - Capacitação de recursos humanos;

IV - Desenvolvimento de estudos, pesquisas e experimentações;

$\mathrm{V}$ - Produção e divulgação de material educativo;

VI - Mobilização social;

VII - Gestão da informação ambiental;

VIII - Monitoramento, supervisão e avaliação das ações. (PETRÓPOLIS, 2012b) ${ }^{16}$

g) há um mesmo entendimento, nas políticas nacional, estadual e municipal, sobre o que seja "educação ambiental formal", abrangendo a educação básica (infantil, fundamental, médio), educação superior, especial, profissional e de jovens e adultos. Entretanto, as políticas nacional e estadual incluem parágrafos sobre a relação entre as diferentes atividades profissionais e o meio ambiente:

Art. 10, § 3o - Nos cursos de formação e especialização técnico-profissional, em todos os níveis, deve ser incorporado conteúdo que trate da ética ambiental das atividades profissionais a serem desenvolvidas (BRASIL, 1999).

\footnotetext{
${ }^{16}$ Na política federal, não constam os incisos I e II.
}

Revista Educação Online, n. 15, jan./abr. 2014, p. 78-102 
Art. 10, $\S 1^{\circ}$ - Em cursos de formação superior e especialização técnico-profissional, em todos os níveis, devem ser incorporados conteúdos que tratem das interações das atividades profissionais com o meio ambiente natural e social (RIO DE JANEIRO, 1999).

As políticas nacional e estadual apresentam uma mesma compreensão sobre a formação inicial de professores e as regras para o funcionamento das instituições de ensino:

Art. 11. A dimensão ambiental deve constar dos currículos de formação de professores, em todos os níveis e em todas as disciplinas.

Art. 12. A autorização e supervisão do funcionamento de instituições de ensino e de seus cursos, nas redes pública e privada, observarão o cumprimento do disposto nos arts. 10 e 11 desta Lei. (BRASIL, 1999)

Em relação à formação continuada de professores, a política nacional determina no Art. 11, "Parágrafo único. Os professores em atividade devem receber formação complementar em suas áreas de atuação, com o propósito de atender adequadamente ao cumprimento dos princípios e objetivos da Política Nacional de Educação Ambiental” (BRASIL, 1999), enquanto a política estadual inclui, além dos professores, os "animadores culturais" (RIO DE JANEIRO, 1999).

Dessa forma, cumpre registrar, que a lei municipal não trata da formação inicial e continuada de professores, considerada um dos problemas centrais ao desenvolvimento da educação ambiental no espaço formal (LOUREIRO; COSSIO, 2007). Ressalte-se que, na Minuta de Projeto de Lei produzida pela Câmara Técnica de Educação Ambiental do COMDEMA, esses aspectos eram considerados:

Art.11 Devem constar dos currículos dos cursos de formação de professores, em todos os níveis e nas disciplinas, os temas relativos à dimensão ambiental e suas relações entre o meio social e o natural.

Art. 12 - Os professores e educadores ambientais, em atividade na rede pública de ensino, devem receber formação complementar em suas áreas de atuação, com o propósito de atender adequadamente ao cumprimento dos objetivos e princípios da Política Estadual de Educação Ambiental. (PETRÓPOLIS, 2011)

No que se refere a outro aspecto central da educação ambiental, cabe destacar que somente a Política Nacional de Educação Ambiental aborda a não disciplinaridade da educação ambiental, conforme proposto pelo MEC (BRASIL, 1997b; 1998b), bem como suas exceções:

$\S 10$ A educação ambiental não deve ser implantada como disciplina específica no currículo de ensino.

$\S 20$ Nos cursos de pós-graduação, extensão e nas áreas voltadas ao aspecto metodológico da educação ambiental, quando se fizer necessário, é facultada a criação de disciplina específica.

h) a educação ambiental não formal é definida de modo semelhante nas três esferas governamentais, sendo que a municipal copia literalmente a política estadual: "Art. 14 - 
Entende-se por educação ambiental não formal as ações e práticas educativas voltadas à sensibilização da comunidade, organização, mobilização e participação da coletividade na defesa da qualidade do meio ambiente" (RIO DE JANEIRO, 1999), cabendo ao poder público incentivar a difusão de programas e campanhas de EA, através dos meios de comunicação, da participação da escola e universidades, de organizações não governamentais, de empresas e órgãos públicos em programas de $E A$, da sensibilização da sociedade, em geral, dos agricultores e trabalhadores rurais, bem como das populações tradicionais sobre a importância das unidades de conservação, e o ecoturismo (PETRÓPOLIS, 2012b);

i) no que se refere à "capacitação de recursos humanos", a política municipal contempla três aspectos, presentes nas políticas nacional e fluminense:

Art. 11 - A capacitação de recursos humanos consistirá, preferencialmente:

I - Na preparação de profissionais orientados para as atividades de gestão e de educação ambiental;

II - Na incorporação da dimensão ambiental na formação, especialização e atualização de profissionais de todas as áreas;

III - Na formação, especialização e atualização de profissionais cujas atividades tenham implicações, direta ou indiretamente, na qualidade do meio ambiente natural e do trabalho. (PETRÓPOLIS, 2012b)

A política estadual inova e é copiada pela municipal, em relação aos agentes sociais e comunitários:

Art. 11, IV - Na preparação e capacitação para as questões ambientais de agentes sociais e comunitários, oriundos de diversos segmentos e movimentos sociais, para atuar em programas, projetos e atividades a serem desenvolvidos em escolas públicas e particulares, comunidades e unidades de conservação. (PETRÓPOLIS, 2012b)

Todavia, mais uma vez, a política municipal se silencia em relação à formação de professores, o que é novamente contemplado pelas políticas nacional e estadual:

Art. $8^{\circ}$, $\S 2^{\circ} \mathrm{A}$ capacitação de recursos humanos voltar-se-á para:

I - a incorporação da dimensão ambiental na formação, especialização e atualização dos educadores de todos os níveis e modalidades de ensino; (BRASIL, 1999)

Art. 15, $\S 1^{\circ}$ - Os órgãos estaduais de educação, através de convênio com universidades públicas, centros de pesquisa e organizações não governamentais, promoverão a capacitação em nível regional dos docentes e dos animadores culturais da rede pública estadual de ensino. (RIO DE JANEIRO, 1999)

j) as três esferas governamentais apresentam um mesmo entendimento sobre as atividades de "estudos, pesquisas e experimentações", exceto no que se refere ao parágrafo único que não consta da política federal:

Art. 12 - Os estudos, pesquisas e experimentações na área de educação ambiental priorizarão:

Parágrafo único - As universidades públicas e privadas deverão ser estimuladas à produção de pesquisas, ao desenvolvimento de tecnologias e à capacitação dos trabalhadores e da comunidade, visando à melhoria das condições do ambiente e da saúde no trabalho e da 
qualidade de vida das populações residentes no entorno de unidades industriais, assim como o desenvolvimento de programas especiais de formação adicional dos professores e educadores ambientais responsáveis por atividades de $1^{\circ}-$ e $2^{\circ}-$ grau. (PETRÓPOLIS, 2012b)

k) a coordenação das políticas de educação ambiental recebe tratamento diferenciado nas esferas governamentais: (1) o governo federal indicou a criação do Órgão Gestor da Política Nacional de Educação Ambiental (OGPNEA), que seria regulamentado em 2002 (BRASIL, 2002), coordenado por representantes dos ministérios da educação e do meio ambiente, com atribuições de definir diretrizes para implementação da Política Nacional de Educação Ambiental, bem como articular, coordenar e supervisionar planos, programas e projetos na área de EA, em âmbito nacional; (2) a lei estadual definiu que cabe às secretarias de educação e de meio ambiente, aos conselhos estadual de educação e de meio ambiente "a função de propor, analisar e aprovar, a política e o Programa Estadual de Educação Ambiental” (Art. 17), ficando o poder executivo

autorizado a constituir o Grupo Interdisciplinar de Educação Ambiental [GIEA], formado por representantes dos órgãos de Meio Ambiente, Educação, Cultura, Ciência e Tecnologia, Saúde, Trabalho, Universidades, da Assembleia Legislativa e de representantes de organizações não governamentais, que terá a responsabilidade do acompanhamento da Política Estadual de Educação Ambiental. (RIO DE JANEIRO, 1999, § 1ํArt. 17)

O poder executivo pode também contribuir na formulação da política e do Programa Estadual de Educação Ambiental. O GIEA tem atribuições semelhantes ao OGPNEA, em âmbito estadual; (3) a legislação petropolitana é bastante sucinta, não definindo prazos e, principalmente, não contemplando a participação social: “Art. 13 - O poder executivo, através de seus órgãos e dos Conselhos Municipais pertinentes, elaborará o Programa Municipal de Educação Ambiental. (PETRÓPOLIS, 2012b) ${ }^{17}$;

I) enquanto a política petropolitana sequer faz menção à sua rede municipal de ensino, a legislação do estado do Rio de Janeiro dedica seis artigos para tratar de aspectos que sua rede de ensino deve priorizar, tais como: (i) a resolução de problemas ambientais locais, conforme preconizado pela Conferência de Tbilisi, tendo como passo inicial a realização de um diagnóstico socioambiental, aspectos tratados em dois artigos:

Art. 18 - As escolas da rede pública estadual de ensino deverão priorizar em suas atividades pedagógicas práticas e teóricas:

I - a adoção do meio ambiente local, incorporando a participação da comunidade na identificação dos problemas e busca de soluções;

\footnotetext{
${ }^{17}$ Por seu turno, a minuta propunha a criação de um Conselho Gestor: "Art. 21 - A Política Municipal de Educação Ambiental será gerida por um Conselho Gestor, a ser criado por decreto do prefeito, composto por, no mínimo, um representante da Secretaria de Meio Ambiente, um da Secretaria de Saúde, um da Secretaria de Educação e um representante da Sociedade Civil (PETRÓPOLIS, 2011).
}

Revista Educação Online, n. 15, jan./abr. 2014, p. 78-102 
Art. 27 - Será instrumento da educação ambiental, ensino formal e não formal, a elaboração de diagnóstico socioambiental a nível local e regional, voltados para o desenvolvimento e resgate da memória ambiental, do histórico da formação das comunidades ou localidades e as perspectivas para as atuais e futuras gerações. (RIO DE JANEIRO, 1999) ${ }^{18}$

ii) a criação de situações de aprendizagem significativas (PERRENOUD, 2000), também foi uma preocupação, recomendando-se a utilização da realidade local como recurso pedagógico na abordagem das questões socioambientais:

Art. 18 - As escolas da rede pública estadual de ensino deverão priorizar em suas atividades pedagógicas práticas e teóricas: (...)

III - As escolas situadas na área de entorno da Baía de Guanabara deverão incorporar, nos seus programas de educação ambiental, o conhecimento e acompanhamento do Programa de Despoluição da Baía de Guanabara - PDBG;

IV - As escolas situadas nas demais baías do Estado, como llha Grande e Sepetiba, assim como as próximas dos rios, lagoas e lagunas fluminenses, deverão adotar em seus trabalhos pedagógicos a proteção, defesa e recuperação desses corpos hídricos.

Art. 21 - As escolas situadas nas áreas rurais deverão incorporar os seguintes temas: programa de conservação do solo, proteção dos recursos hídricos, combate à desertificação e à erosão, controle do uso de agrotóxicos, combate a queimadas e incêndios florestais e conhecimento sobre o desenvolvimento de programas de microbacias e conservação dos recursos hídricos. (RIO DE JANEIRO, 1999)

iii) a inserção da questão ambiental na formação de técnicos:

Art. 19 - As escolas técnicas estaduais deverão desenvolver estudos e tecnologias que minimizem impactos no meio ambiente e de saúde do trabalho, como controle e substituição do CFC (Cloro Flúor Carbono); substituição do amianto e mercúrio e incentivo ao controle biológico das pragas.

Art. 20 - As escolas técnicas e de $2^{0}$ grau deverão adotar em seus projetos pedagógicos 0 conhecimento da legislação ambiental e das atribuições dos órgãos responsáveis pela fiscalização ambiental. (RIO DE JANEIRO, 1999)

Cabe destacar que a Minuta do Projeto de Lei, elaborado pela Câmara Técnica de Educação Ambiental do COMDEMA, atribuía prioridades à rede municipal de ensino que, entretanto, foram retiradas da lei aprovada:

Art. 16 - As escolas da rede pública municipal de ensino deverão incorporar em seus projetos pedagógicos atividades que priorizem as seguintes práticas:

I - a participação da comunidade na identificação dos problemas e busca de soluções;

II - ações de monitoramento e participação em campanhas de defesa do meio ambiente como reflorestamento, coleta seletiva de lixo e de pilhas e baterias de celulares;

III - disseminação de informação sobre as unidades de conservação existentes nos limites e no entorno do município, promovendo sempre que possível visitas a esses espaços protegidos;

IV - adoção de temas relacionados com a proteção, defesa e recuperação dos corpos hídricos existentes no município, com ênfase na Bacia do Piabanha, em seus trabalhos pedagógicos; $\mathrm{V}$ - interação com a gestão da APA-Petrópolis, participando sempre que possível dos projetos e campanhas desenvolvidos por essa unidade de conservação;

${ }^{18}$ A Minuta do Projeto de Lei, elaborada pela Câmara Técnica de EA do Conselho Municipal de Meio Ambiente (COMDEMA) (PETRÓPOLIS, 2011) contemplava uma cópia do artigo 27 da política estadual (RIO DE JANEIRO, 1999).

Revista Educação Online, n. 15, jan./abr. 2014, p. 78-102 
$\mathrm{VI}$ - abordagem de temas relacionados com a conservação do solo, o combate à desertificação e a erosão, controle do uso de agrotóxicos, combate a queimadas e incêndios florestais;

VII - abordagem de temas relacionados a Noções Gerais de Defesa Civil e Percepção de Riscos, conforme previsão da Lei Municipal 6.683/2009. (PETRÓPOLIS, 2011) ${ }^{19}$

m) a formulação e seleção de planos e programas de educação ambiental são tratados, de forma semelhante, pelas políticas nacional e estadual, sendo que essa última, além de incluir "projetos", também atribui prioridade, para recebimento de verbas públicas estaduais, às organizações não governamentais:

Art. 24 - A seleção de planos, programas e projetos de educação ambiental a serem financiados com recursos públicos, deve ser feita de acordo com os seguintes critérios:

I - conformidade com os objetivos, princípios e diretrizes da política estadual de educação ambiental;

II - prioridade de alocação de recursos para iniciativas e ações dos órgãos integrantes do Sistema Estadual de Educação, do Sistema Estadual de Meio Ambiente e de organizações não governamentais;

III - coerência do plano, programa ou projeto com as prioridades socioambientais estabelecidas pela Política Estadual de Educação Ambiental;

IV- economicidade medida pela relação entre a magnitude dos recursos a serem aplicados e o retorno social e propiciado pelo plano, programa ou projeto proposto.

Parágrafo único - Na seleção a que se refere o "caput" deste artigo, devem ser contemplados, de forma equitativa, os programas, planos e projetos das diferentes regiões do estado. (RIO DE JANEIRO, 1999)

A política municipal somente inclui como critério de seleção a "conformidade com os objetivos, princípios e diretrizes da Política Municipal de Educação Ambiental”, a serem financiados pelo Fundo Municipal de Conservação Ambiental e ICMS Verde (Art. 14). Semelhante à política estadual, a lei municipal (PETRÓPOLIS, 2012b) determina a criação de um Cadastro Municipal de Educação Ambiental (Art. 16), que subsidiará o Programa Municipal de Educação Ambiental, esse último mencionado pela primeira vez nesse documento;

n) em aparente desacordo com as legislações federal e estadual, no que se refere ao financiamento da educação ambiental, a política petropolitana não faz menção ao Fundo Municipal de Meio Ambiente ou aos programas de assistência técnica e financeira relativos ao meio ambiente:

Art. 18. (VETADO) Devem ser destinados a ações em educação ambiental pelo menos vinte por cento dos recursos arrecadados em função da aplicação de multas decorrentes do descumprimento da legislação ambiental. (SOTERO, 2008, p. 149-150)

Art. 19. Os programas de assistência técnica e financeira relativos a meio ambiente e educação, em níveis federal, estadual e municipal, devem alocar recursos às ações de educação ambiental. (BRASIL, 1999)

Art. 25 - Os recursos do FECAM poderão ser destinados a programas e projetos de educação ambiental desde que aprovados pelo seu Conselho Gestor, nos termos do Art. 263 da Constituição Estadual.

\footnotetext{
${ }^{19}$ A Lei 6.683/2009 (PETRÓPOLIS, 2009a) foi anteriormente abordada ao tratarmos da transversalidade da temática ambiental proposta pelo Plano Municipal de Educação (PETRÓPOLIS, 2009).
}

Revista Educação Online, n. 15, jan./abr. 2014, p. 78-102 
Art. 26 - Os programas de assistência técnica e financeira relativos a meio ambiente e educação, em nível estadual, devem alocar recursos às ações de educação ambiental. (RIO DE JANEIRO, 1999)

Art.17 - As despesas decorrentes desta Lei correrão por conta das dotações próprias, suplementadas se necessário. (PETRÓPOLIS, 2012b) ${ }^{20}$

\section{Considerações finais}

Consolidando argumentos. No que se refere às concepções de desenvolvimento sustentável (DS), de meio ambiente (MA) e de EA, verificamos que enquanto a Lei Orgânica (LOM) não faz menção ao DS, o Plano Municipal de Educação (PME) o cita, mas não o define. Contraditoriamente, a LOM apresenta concepções reducionista e socioambiental de MA, em diferentes momentos, enquanto no PME não encontramos a categoria "meio ambiente". Sob uma abordagem conservacionista, restrita aos aspectos naturais do meio ambiente, na LOM há uma menção à EA, enquanto que o PME, revelando alguma conexão com as conquistas ocorridas, determina a abordagem transversal da EA no ensino fundamental e, inovando, também no ensino médio. Conclui-se que poucas conquistas da EA crítica foram incorporadas à Lei Orgânica ou ao Plano Municipal de Educação.

A Política Municipal de Educação Ambiental de Petrópolis (PMEAP) incorpora as abordagens críticas de MA, DS e EA, presentes nas políticas nacional e estadual de EA, uma conquista dos movimentos ambientalistas. Entretanto, cabe destacar algumas ausências na PMEAP: (a) diferente da minuta produzida pela Câmara Técnica de EA do COMDEMA (PETRÓPOLIS, 2011), não trata da formação inicial e continuada de professores, um aspecto central para o desenvolvimento de uma perspectiva crítica de EA; (b) apesar de citar o Sistema Municipal de Meio Ambiente, não especifica os órgãos a ele vinculados ou suas atribuições; (c) não cria órgão específico para coordenar a Política/Programa Municipal de EA, nem incorpora a participação social nesse processo, desconsiderando a importância da desarticulação das políticas setoriais em governos de coalizão; (d) não inclui especificidades da rede municipal de ensino; (e) não leva em consideração os problemas socioambientais locais ou a característica de se tratar de uma cidade imperial, com expressivo patrimônio histórico-ambiental, que

\footnotetext{
${ }^{20} \mathrm{Na}$ Minuta do Projeto de Lei constava: "Art. 17 - A seleção de planos, programas e projetos de educação ambiental a serem financiados com recursos públicos, deverá ser feita em conformidade com os objetivos, princípios e diretrizes da Política Municipal de Educação Ambiental. Parágrafo 1ํ: das verbas disponíveis no Fundo Municipal de Conservação Ambiental, 20\% deverão ser aplicadas em projetos de Educação Ambiental. Parágrafo $2^{\circ}$ : das verbas repassadas ao município como ICMS verde, $20 \%$ deverão ser destinadas a projetos de educação ambiental" (PETRÓPOLIS, 2011).
}

Revista Educação Online, n. 15, jan./abr. 2014, p. 78-102 
deveriam ser considerados temáticas centrais nas atividades de EA, o que contribuiria para a construção de situações de aprendizagem significantes (PERRENOUD, 2000) ${ }^{21}$.

Considerando os vários e graves problemas identificados, sugerimos que, em uma possível revisão dessa lei ou sua regulamentação, os trabalhos legislativos sejam precedidos pelo desenvolvimento de alguns levantamentos e estudos, como os destacados abaixo:

1. semelhante a vários municípios e estados, realização de consulta pública, via internet, visando a garantir e estimular a participação dos diferentes segmentos da nossa sociedade ${ }^{22}$;

2. levantamento das políticas municipais de educação ambiental de cidades com características semelhantes a Petrópolis: topografia, clima, patrimônio histórico-ambiental, tais como: região serrana fluminense, Parati, região do médio Paraíba;

3. levantamento e identificação de aspectos centrais à realidade petropolitana, que necessitam ser contemplados na legislação municipal (rede municipal de ensino, áreas de risco, patrimônio histórico-ambiental), como, por exemplo, a inclusão do "Centro de Estudos e Pesquisa em Educação Ambiental", um espaço privilegiado para formação de professores e visitação de escolas;

4. levantamento de programas, projetos, atividades de educação ambiental, desenvolvidos em Petrópolis, pelas diferentes esferas governamentais, visando a também reunir subsídios e sugestões;

5. realização de seminários com especialistas em educação ambiental (pesquisadores e gestores municipais, estaduais, federais), com o objetivo de incorporar o conhecimento teórico e prático acumulado sobre os desafios colocados à formulação e implementação de políticas públicas de educação ambiental.

\section{Referências bibliográficas}

ACSELRAD, H.; LEROY, J. Novas premissas da sustentabilidade democrática. Rio de Janeiro: FASE, 1999 (Cadernos de Debate Brasil Sustentável e Democrático, 1).

BRASIL. Constituição da República Federativa do Brasil. In. Diário Oficial [da] República Federativa do Brasil, 5 out. 1988.

Decreto no 4.281, de 25 de junho de 2002. Regulamenta a Lei no 9.795, de 27 de abril de 1999, que institui a Política Nacional de Educação Ambiental, e dá outras providências. In. Diário Oficial [da] República Federativa do Brasil, 26 jun. 2002.

\footnotetext{
${ }^{21}$ Conforme depoimento obtido em entrevista junto a um membro do COMDEMA, os dispositivos que constavam na minuta (PETRÓPOLIS, 2011), relacionados às atribuições do poder executivo municipal, foram vetados (ausências aqui destacadas), sob a alegação de interferência em competências do poder executivo, em razão de o projeto de lei ter sido iniciativa do poder legislativo.

${ }_{22}$ Sobre uma exitosa experiência de participação social na construção da Política e do Programa Municipal de EA em Mesquita (RJ), ver Santos et alli. (2011).
}

Revista Educação Online, n. 15, jan./abr. 2014, p. 78-102 
Lei no 6.938 , de 31 de outubro de 1981. Dispõe sobre a Política Nacional do Meio Ambiente, seus fins e mecanismos de formulação e aplicação, e dá outras providências. In. Diário Oficial [da] República Federativa do Brasil, 02 set. 1981.

BRASIL. Lei no 9.795, de 27 de abril de 1999. Dispõe sobre a educação ambiental, institui a Política Nacional de Educação Ambiental e dá outras providências. In. Diário Oficial [da] República Federativa do Brasil, 28 abr. 1999.

. Ministério da Educação. Conselho Nacional de Educação. Resolução № 2, de 15 de junho de 2012. Estabelece as Diretrizes Curriculares Nacionais para a Educação Ambiental. In. Diário Oficial [do] Poder Executivo, 18 jun. 2012.

BRASIL. Ministério da Educação. Secretaria de Educação Fundamental. Parâmetros curriculares nacionais - primeiro e segundo ciclos do ensino fundamental: introdução aos parâmetros curriculares nacionais. Brasília: MEC/SEF, 1997a.

. Parâmetros curriculares nacionais - primeiro e segundo ciclos do ensino fundamental: tema transversal meio ambiente e saúde. Brasília: MEC/SEF, 1997b.

Parâmetros curriculares nacionais - terceiro e quarto ciclos do ensino fundamental: introdução aos parâmetros curriculares nacionais. Brasília: MEC/SEF, 1998a.

. Parâmetros curriculares nacionais - terceiro e quarto ciclos do ensino fundamental: tema transversal meio ambiente. Brasília: MEC/SEF, 1998b.

Referencial curricular nacional para a educação infantil. Brasília: MEC/SEF, 1998c.

Programa parâmetros em ação - meio ambiente na escola. Brasília: MEC/SEF, 2001.

BRASIL. Ministério do Meio Ambiente. Diretoria de Educação Ambiental/Ministério da Educação e Cultura. Coordenação Geral de Educação Ambiental. Programa nacional de educação ambiental - ProNEA. 3. ed. Brasília: MMA/DEA;MEC.CGEA, 2005.

BRASIL. Ministério do Meio Ambiente. Instituto Brasileiro do Meio Ambiente. Programa nacional de capacitação de gestores ambientais - Política nacional de meio ambiente. Brasília: MMA/IBAMA, 2006. (Cadernos de Formação, Volume 1)

. Plano de Manejo da APA Petrópolis - Resumo Executivo. Brasília: MMA/IBAMA, 2007.

BRASIL. Órgão Gestor da Política Nacional de Educação Ambiental. Programa nacional de formação de educadoras(es) ambientais: por um Brasil educado e educando ambientalmente para a sustentabilidade (ProFEA). Brasília: OGPNEA, 2006. (Série Documentos Técnicos, oㅡ 8)

DELUIZ, N.; NOVICKI, V. Trabalho, meio ambiente e desenvolvimento sustentável: implicações para uma proposta de formação crítica. In. Boletim Técnico do SENAC, Rio de Janeiro, v. 30, n. 2, p. 18-29, maio/ago 2004.

FARJALLA, R. Implementação de políticas de Educação Ambiental no Município de Petrópolis (RJ): Curso de Form-Ação em Educação Ambiental e Agenda 21 Escolar: Formando Elos de Cidadania. Petrópolis: Universidade Católica de Petrópolis. Dissertação (Mestrado em Educação), 2013.

GRÜN, M. Ética e educação ambiental: a conexão necessária. 3ª ed. São Paulo: Papirus, 1996. GUIMARÃES, M. A formação de educadores ambientais. Campinas, SP: Papirus, 2004.

LAYRARGUES, P. P. Do ecodesenvolvimento ao desenvolvimento sustentável: evolução de um conceito. Proposta, v. 25, n.71, p. 05-10, 1997.

; LIMA, G. F. da C. Mapeando as macrotendências político-pedagógicas da Educação Ambiental contemporânea no Brasil. In: ENCONTRO PESQUISA EM EDUCAÇÃO 
AMBIENTAL, VI, 2011, Ribeirão Preto. Anais... Ribeirão Preto: EPEA, 2011. 1 CD-ROM, p. 115.

LOUREIRO, C. F. B.; COSSIO, M. F. B. Um olhar sobre a educação ambiental nas escolas: considerações iniciais sobre os resultados do projeto "O que fazem as escolas que dizem que fazem educação ambiental?". In. BRASIL. Ministério da Educação. Ministério do Meio Ambiente. Vamos cuidar do Brasil: conceitos e práticas em educação ambiental na escola. Brasília: MEC/MMA;UNESCO, 2007. p. 57-63.

MARX, K. O Capital: crítica da economia política. São Paulo: Nova Cultural, 1988.

NOVICKI, V. Políticas e práticas de educação ambiental em Petrópolis (RJ). Petrópolis: Projeto de Pesquisa, 2010.

OLIVEIRA, A. G. de. Políticas públicas educacionais dos municípios do estado do RJ : relações com os indicadores de qualidade 2005 e 2007. Rio de Janeiro, 2010. Dissertação (Mestrado em Educação) - PUC-Rio. Rio de Janeiro, 2010.

PERRENOUD, P. Dez novas competências para ensinar. Porto Alegre: Artes Médicas Sul, 2000.

PETRÓPOLIS (Município). Lei Orgânica do Município de Petrópolis. In. Diário Oficial [do] Município de Petrópolis, 07 abr. 1990.

Lei Orgânica do Município de Petrópolis - Edição Anotada. In. Diário Oficial [do] Município de Petrópolis, 3ª Edição Anotada, 16 dez. 2000.

- Lei Orgânica do Município de Petrópolis - Edição Revisada (Emenda no 25, de 10 de outubro de 2012). In. Diário Oficial [do] Município de Petrópolis, 11 out. 2012a.

. Lei $\mathrm{n}^{\circ}$ 6.362, de 02 de junho de 2006. Cria o Conselho Municipal de Meio Ambiente e dá outras providências. In. Diário Oficial [do] Município de Petrópolis, 05 jun. 2006.

. Lei no 6.683 , de 04 de setembro de 2009. Torna obrigatória a inclusão do ensino de noções de defesa civil na rede de ensino público municipal. In. Diário Oficial [do] Município de Petrópolis, 05 set. 2009a.

. Lei no 6.709, de 15 de dezembro de 2009. Institui o Plano Municipal de Educação. In. Diário Oficial [do] Município de Petrópolis, 16 dez. 2009b.

. Lei no 7034 , de 28 de dezembro de 2012. Institui princípios e diretrizes para a Política Municipal de Educação Ambiental no Município de Petrópolis. In. Diário Oficial [do] Município de Petrópolis, 29 dez. $2012 b$.

PETRÓPOLIS (Município). Secretaria Municipal de Educação. Conselho Municipal de Educação. Plano Municipal de Educação - Petrópolis - RJ: 2009-2018. Petrópolis: SEMED/COMED, 2009.

PETRÓPOLIS (Município). Conselho Municipal de Meio Ambiente. Câmara Técnica de Educação Ambiental. Minuta da Lei de Política Municipal de Educação Ambiental de Petrópolis. Petrópolis: COMDEMA, 2011 (mimeo).

RIO DE JANEIRO (Estado). Lei no 3325, de 17 de dezembro de 1999. Dispõe sobre a educação ambiental, institui a política estadual de educação ambiental, cria o Programa estadual de Educação Ambiental e complementa a Lei Federal no 9.795/99 no âmbito do Estado do Rio de Janeiro. In. Diário Oficial do Estado do Rio de Janeiro, 18 dez. 1999.

SANTOS, A. M. M.; LOUREIRO, C. F. B.; BEZERRA, C. A. M. Política e programa de Educação Ambiental no município de Mesquita/RJ: um caso de participação popular na construção de uma política pública. In ENCONTRO PESQUISA EM EDUCAÇÃO AMBIENTAL, VI, 2011, Ribeirão Preto. Anais... Ribeirão Preto: EPEA, 2011. 1 CD-ROM, p. 1-13.

Revista Educação Online, n. 15, jan./abr. 2014, p. 78-102 
SOTERO, J. P. O financiamento público da Política Nacional de Educação Ambiental: do veto do artigo 18 às novas estratégias de financiamento. Brasília, 2008. Dissertação (Mestrado em Desenvolvimento Sustentável) - Universidade de Brasília, Brasília, 2008.

TRAJBER, R.; MENDONÇA, P. R. (Orgs.). Educação na diversidade: o que fazem as escolas que dizem que fazem educação ambiental. Brasília: Secretaria de Educação Continuada, Alfabetização e Diversidade, 2006. 256 p. (Coleção Educação para Todos, Série Avaliação; n. 6, v. 23).

VEIGA, A.; AMORIM, E.; BLANCO, M. Um retrato da presença da educação ambiental no ensino fundamental brasileiro : o percurso de um processo acelerado de expansão. Brasília: Instituto Nacional de Estudos e Pesquisas Educacionais Anísio Teixeira, 2005. 